\title{
Blended Learning Applied to an Introductory Course on Conceptual Physics
}

\author{
doi:10.3991/ijoe.v6i3.1303 \\ P. Teherán, J. G. Carriazo and J. C. León \\ Universidad Nacional de Colombia, Bogotá, Colombia
}

\begin{abstract}
In this paper, we show aspects of the commencement of a novel introductory Physics course with conceptual emphasis. An instructional flexible design in the format of blending learning is presented that combines master classes via teleconference with additional activities in a virtual environment of learning orchestrated by LMS Blackboard. In the forums, workshops and virtual laboratories the impact is evaluated as a grading system based on Continuous Personalized Evaluation.
\end{abstract}

Index Terms-Blended-learning, Conceptual Physics, Continuous Personalized Assessment, ICT.

\section{INTRODUCTION}

The Universidad Nacional de Colombia adopts the Special Program of Admission and Academic Mobility (PEAM) for the headquarters of national presence with the approval of the arrangement 025 of 2007 [1]. Higher University Council: Amazonía, Caribe and Orinoquía. This program provides students from the mentioned regions access to 56 undergraduate programs available in the capital cities Bogota, Medellin, Manizales, Palmira belonging to 4 of the 7 most consolidated headquarters of the National University of Colombia and improves access conditions to quality higher education in these regions by providing about 150 places for applicants who reside in the departments of Arauca, Guainía, Casanare, Vichada, Guaviare, the archipelago of San Andrés, Providencia, Santa Catalina and the Amazon. Applicants may compete for up to 3 career choices, submit the admission test, join a basic level of common courses for up to 4 semesters at the headquarters of residence and then move to complete his degree at the headquarter of his preference.

This occurs as part of reforms introduced several years ago at the National University of Colombia where the introduction of Information Technologies and Communication Technologies (ICT) has been proposed [2],[3],[4]; however, in the Colombian university context beyond agreements [4], regulations and discussions [2], [3] about the benefits, challenges and prospects of application of ICT, few contributions so far account for concrete experiences and validate the positions taken for or against the illnamed Virtual University. Objective reasons such as the need to expand coverage, introduction of "new practices that encourage the development of the capacity of teaching and learning, criticism and innovation, teamwork, attitudes of solidarity, individual and collective responsibility [4]", require insurmountable challenges to the paradigms of higher education based on traditional systems of classroom teaching. ICTs are meant to play in addressing these needs of the modern, globalized world.
On the other hand, statistics show that among the subjects with the highest rate of repetition is physics, particularly in the first semester which produces the early dropout of some university students and affects the permanence time of some others [4]. The latter aspect of this chronic disease, which results from the incongruity of learning styles and teaching methods, inadequate training in basic and intermediate levels of secondary education, coupled with lack of autonomy and discipline of the learners, are prime targets to attack in the proposal for a new course on "Fundamentals of Physics" designed in the blended-learning modality we describe below.

\section{CURRICULAR DESIGN}

Traditionally the subject "Fundamentals of Physics" of the undergraduate program of Physics, at the Universidad Nacional de Colombia has been an introductory course, face, theoretical, conducted in order to provide an overview of physics from the classical to the quantum and relativistic interpretation of nature. A course as large has been taught with different methodologies, some based on lectures by the teacher in charge and other, sometimes somewhat disjointed in style, by a group of expert teachers on each subject, selected readings and occasional exercise sessions. However, with traditional tools it's complex to achieve the proposed objective which has generally led to a bias towards the topics of preference of each teacher with a resulting reduction in program content viewed by students.

The new proposal aims to provide an introduction to Physics from a point of view entirely conceptual, going from Mechanics, traditionally treated in all introductory courses of Physics in a so extensive way that often ends up taking all the available time, to Modern Physics, including Atomic and Molecular Physics, and Relativity. The latter areas are usually neglected in first and second year Physics courses and their concepts often turn out to be simpler than those of Mechanics, yet more exciting and motivating to student's curiosity.

The content was divided in 9 parts. First one corresponds to an introductory chapter to science and the others to different disciplines of Physics, with a different number of chapters according to necessity: Mechanics (10 chapters), Properties of Matter (4 chapters), Heat (4 chapters), Sound (3 chapters), Electricity and magnetism (4 chapters), Light (4 chapters), Atomic and Nuclear Physics (5 chapters), Relativity (2 chapters). In total the course consists of 36 chapters treated in 16 weeks, the duration of each academic semester, with 4 hours per week of class. The operative part, linked to the mathematics, is left aside. Although this is necessary in order to express the laws of Physics in an appropriate language for the quantitative analysis of physical phenomena, it doesn't constitute the 
mainstay of this science; concepts are, so most of them are studied in a purely conceptual way.

\section{A. Evaluation and grading system}

In order to promote an approach to teaching skills and to restructure the traditional evaluation scheme conducive to monitoring the learning process instead of the teaching process we decided to design an evaluation and rating system based on Continuous Personalized Evaluation [6],[8] consistent with the guidelines of the EEES and the Tuning project [8],[9]. System should include the possibility to monitor and quantify classroom and extra class activities. So we chose a system $100 \%$ supported on the Blackboard LMS (Fig. 2). Thus the $85 \%$ of the evaluation and grading process was conducted on extra class time in the following way:

By recommendation of the teacher in charge an exercise of citizenship skills was performed in a virtual forum in order to discuss the percentages of ratings (see Table 1). The weighting in mention was made by rating categories as follows:

TABLE I.

CATEgories and Percentage Ranges of THE GRAding System

\begin{tabular}{|c|c|c|}
\hline Category & $\begin{array}{c}\# \\
\text { Grades }\end{array}$ & Importance \\
\hline Duties & 6 & $0 \%-5 \%-10 \%$ \\
\hline Attendance & 26 & $5 \%-10 \%$ \\
\hline Evaluations & 8 & $15 \%-20 \%-25 \%-30 \%$ \\
\hline Forum & 8 & $10 \%-15 \%$ \\
\hline Workshops & 6 & $5 \%-10 \%$ \\
\hline Quices & 6 & $5 \%-10 \%$ \\
\hline Final CPE & 1 & $15 \%-25 \%$ \\
\hline
\end{tabular}

For convergence purposes voting was made iterative reporting each 12 hours the results, after 3 iterations consensus was reached on one of the 466 options that add to $100 \%$.

\section{B. Orientation of the Course}

The course is designed for students of Engineering and Basic Sciences. It's offered from the main campus of the University located in Bogotá the capital of Colombia to other three campuses located on Arauca, San Andrés and Leticia. There are 70 enrolled students in total.

\section{METHODOLOGY}

There are three important moments on the course: magistral classes, reading the workbook and activities on the Virtual Classroom. These activities are complementary and in no case one replaces the other. The lectures provide a general vision of the subject following the same order of readings. These are received via teleconference by students on different campuses (Fig. 1).

Students have to read contents to be treated before class in order to reinforce concepts individually and identify subjects in which main difficulties are present.

This material is the base of the programmed activities on the Virtual Classroom (Fig. 2). The latter contains a set of animated contents, java applets and different types of evaluations that allow the student experiment to his taste with chosen examples from each treated subject and the teacher in charge to monitor individual and group understanding the viewed contents.

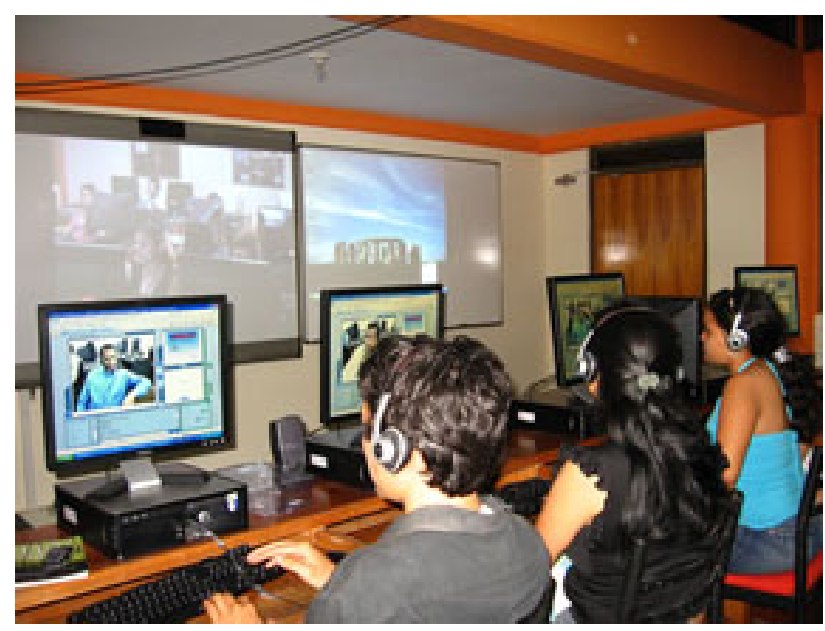

Figure 1. Classroom on the campus of Arauca

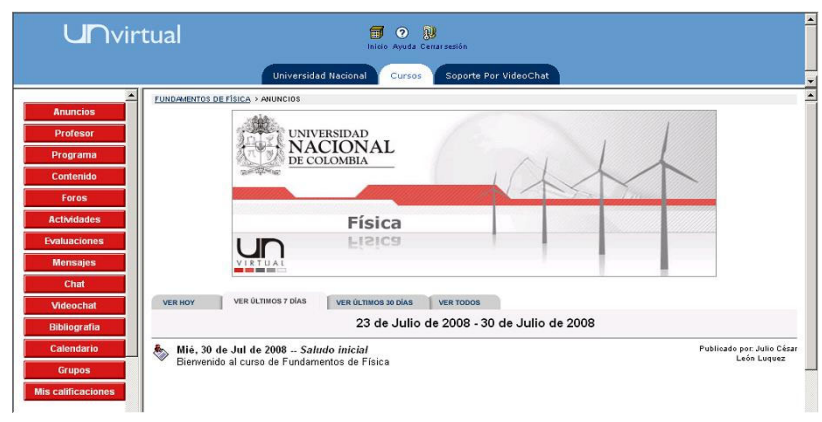

Figure 2. Screenshot of the Virtual Classroom

\section{DISCUSSION}

\section{A. Curricular Design}

The sequence and amount of content has been satisfactory for the 16 weeks of programming for the course. Students from Orinoquía received $35 \%$ of the sessions with the presence of the teacher in charge, all other sessions were made by teleconference. Because on the Campus there is a lack of teachers, students reflected in surveys and forums the desire to have an exclusive tutor, virtual or face. Experience resulted satisfactory and motivating for the students who express that teleconferences were effective and that the course didn't represent an unreachable challenge. The area with less success on evaluations was Mechanics, due in part to his extension (10 chapters) and the lack of adaptation to the virtual tools on the first weeks of class.

\section{B. Assesment System}

The democratization of the grade was welcomed by the majority of students who felt interesting to participate in the determination of the percentages because it allowed them to correlate best efforts to the weighting of them. The rating system of forums was widely criticized at the beginning of the semester, then an adjustment to the values of quality and quantity of publications coupled with the introduction of co-evaluation schemes changed the perception about this style of assessment. This was reflected in the final survey of the course.

The diversity of activities avoids the tension towards the evaluations, this contributed to greater autonomy and self regulation of student's time. The performance of stu- 
dents at Arauca was 30\% higher than the performance of students in Bogotá, this is correlated with a lower rate of communication of students with the teacher in charge in the second campus.

Another innovation we hope to have future consequences is the introduction of assessments via Virtual Classroom with large sets of questions, of which each student must answer a number that is chosen randomly and automatically by the LMS. This has allowed students to be more responsible with managing their time according to their academic activities and extra-academic, even more decreases the possibility of copy or impersonation since login in the course requires a username and private password and has permitted the implementation of pedagogical assessment strategies impossible in courses entirely face, as are the possibility that the student has several attempts to conduct an assessment and that each student faces a test with different questions on each attempt.

Finally, grading system is inspired on Continuous Personalized Assessment ${ }^{7}$, which proposes that assessing as many involved variables in the teaching-learning process mitigates the stressful effect of evaluations and tends to a more autonomous management by the student of the learning process. Particularly, active participation of students has been disposed in the weighting of grades between ranges established by the teacher. A total of 6 categories of evaluations measuring from the attendance to forums allow a more detailed screening useful to evaluate critical cases of students who face the loss or low performance on the course.

\section{Methodology}

The virtual classroom has enabled the introduction of asynchronous communication teacher-student and studentstudent, plus the inclusion of activities based on java applets that simulate laboratory practice. The first has been important since much of the group of students taking the course is in a remote region of the country.

This has expanded coverage, maintaining a good level of education. The implementation of virtual discussion forums has encouraged the construction of knowledge in a cooperative manner on students. Initially, the participation of teacher and tutor was absent, and the shares and discussions presented by the students, sometimes were not completed, and others were oriented incorrectly.

Currently, the inclusion of suggestions and clarifications on their part, contributed to better development of the discussions raised in this space. As a result, the forums have become the primary means of introducing complementary and alternative content to those seen in class and of interest to students and have enabled the identification, monitoring and constant correction of error patterns or erroneous preconceptions within the population of the course. An increase of the communication student-student and student-teacher is evidenced by a volume of more than 400 emails and about 3,500 publications in the forums for a population of 70 students. Simulated laboratories have enabled the introduction of some important concepts such as measurement, analysis of graphs and theory of errors, impossible to deal with in absence laboratories. We also believe that these basic concepts are needed since they constitute the essence in the area of Experimental Physics, and are never treated in introductory courses. It is usual that such concepts are introduced in experimental, in which due to lack of student's previous experience in this regard, there are difficulties in its appropriation.

\section{REACTIONS OF STUDENTS AND TEACHERS}

The phase coupling of the students to new tools such as LMS, virtual assessment, forums, chat and video-chat advice, virtual workshops, use of animations, simulations and virtual experiments was successful. The use of qualifying criteria based on CPA has been accepted with pleasure, although with natural controversy and opposition from those who prefer the traditional schemes of classification. The community of physics teachers that have adopted ICT elements as part of their day teaching is still small, but growing. Yet few courses designed entirely with the use of multimedia and virtual tools. There is skepticism regarding the implementation of LMS platform assessments, particularly round the ghost of the identity of the respondent to evaluations, however the introduction of extensive question sets as those built for this year, about 4,000 questions, and their application randomly for each trial and each student has been welcome and tends to give credibility to online evaluation

\section{FUTURE WORK}

For the upcoming launch, two more headquarters of the University will join: Amazonía and Caribe. The geographic location of the headquarters is shown in Fig. 3.

One of the big advantages with the introduction of the virtual classroom is that all information and activities carried out by this are recorded digitally. This facilitates to a

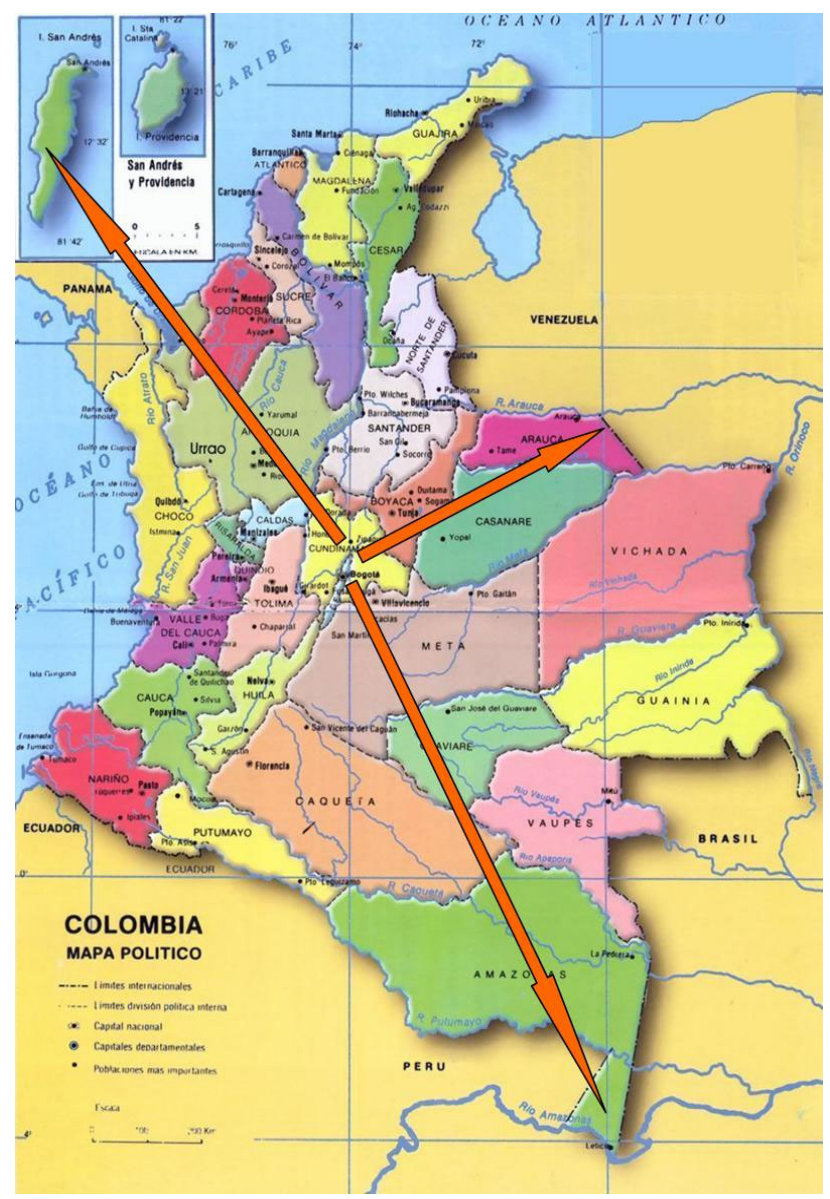

Figure 3. Location of involved campuses [10]. 
large extent the processing of such information. For example, it is expected that analysis of the contributions made in the forums allow to establish different behaviors of students. According to these, personalized teaching strategies will be implemented to allow better use of the course for each one. Furthermore, based on the above information and the collected responses to the questions of the tests performed in this first experiment, is expected to identify error patterns and concepts difficult to grasp for the group so that in the future more emphasis could be made on these contents, and that some of the tests are evaluated automatically, using the tools provided by LMS. This would implicate a great relief in the revision work of tests plus the possibility to implement innovative models of quantitative analysis of multiple-choice tests proposed recently [7].

\section{CHALLENGES}

The suitability of new forms of the relation teacherstudent and student-student to teaching-learningdevelopment processes requires high doses of creativity for the reinvention of the role played by each of the actors in the new scenario of a globalized world dominated by large volumes of information. The critical attitude towards an evident grow of information requires to return the fundamental aspects of our teaching labor, aspects such as the domain of oral and written tools in teachers and students, improvement of negotiation skills for collaborative work, autonomy and logical reasoning, acceptance of diversity of thought and cultural capital in pupils.

The end of semester survey suggests that is necessary to promote collaborative work, make more dynamic magistral sessions with discussions between students, take advantage of online assessment capabilities to record, display and monitor real-time assimilation of concepts.

On the other hand it is necessary to adjust instructional time learning the rhythms of populations, particularly the issue requires the redesign of Mechanics.

The proposed system of common courses to Headquarters of National Presence (SPN) assumes that the design should exhibit scaling capabilities; that is, the possibility of increasing the number of courses with completes flexibility without compromising on the quality of teachinglearning-development. In version II-2008 is expected to launch a pyramidal system of tutors for 4 sites simultaneously in order to lessen the impact on extra-class attention on the teacher in charge

Finally, we hopes to expand the amount of applets, Physlets and question sets in order to consolidate the assessment of teaching-learning process.

\section{CONCLUSIONS}

The new model of course has been launched successfully and has validated the assessment system.

The adaptation of students to the new virtual environment has been rapid and satisfactory performance.

Innovations in the course have had positive effects by allowing a high degree of autonomy, self-regulation and responsibility in students.

Communication student-student and student-teacher has increased.

\section{ACKNOWLEDGMENT}

The authors acknowledge the support received from the Universidad Nacional de Colombia for the completion of these educational experiences, and are also grateful to the National Division of Academic Virtual Services, DNSAV, for their technical and logistical support.

\section{REFERENCES}

[1] Arrangement 025, Higher University Council, Universidad Nacional de Colombia. Act 10, October 9 of 2007. Available: http://www.unal.edu.co/secretaria/normas/csu/2007/A0025_07S.p df

[2] Universidad Nacional de Colombia (2009). Reforma Académica [Online]. Available: http://www.unal.edu.co/reforma/academica/

[3] Redacción Unimedios (2004, October 24). Innovación Institucional Veinte Meses de Discusión en la UN. [Online] Available:http://historico.unperiodico.unal.edu.co/ediciones/65/06.htm

[4] M. Palacios (2003, Sept. 30). Hacia la Innovación Institucional en la Universidad Nacional [Online]. Available: http://www.udenar.edu.co/viceacademica/acre files/REVOLUCIO N\%20EDUCATIVA/INNOVACION\%20INSTITUCIONAL\%20 UNAL.PDF

[5] Arrangement 033, Higher University Council, Universidad Nacional de Colombia. Act 11, November 26 of 2007. Available: http://www.unal.edu.co/reforma/academica/documentos/vicerrecto ria/Acuaerdo_033/A0033_07S.pdf

[6] P. Teherán; C. A. Cuesta, "Valoración de cambios conceptuales en estudiantes de Física I (Evaluation of Conceptual Changes of Physics I Students)”, in Experiencias Significativas en Innovación Pedagógica, G. Hernández and F. A. Vargas, Eds. Bogotá, Colombia: Unibiblos, 2006, pp. 196-205. Available: http://disi.unal.edu.co/ gjhernandezp/esip/esip.pdf

[7] L. Bao, "Dynamics of Student Modeling: A Theory, Algorithms and Applications to Quantum Mechanics” Ph.D. Dissertation, Faculty of the Graduate School, University of Maryland, College Park, MD, 1999. Available: http://www.physics.ohiostate.edu/ lbao/Thesis/Bao_Thesis_v021600.zip

[8] V. García, Educación Personalizada, Madrid, España: Ediciones Rialp S.A., 1988.

[9] M. Delgado-García, R. Borge-Bravo, J. García-Albero, R. OliverCuello, L. Salomón-Sancho, "Competencias y diseño de la evaluación continua y final en el espacio europeo de educación superior (Competencies and Design of the Continuous and Final Assesment in the European Higher Education Area)", 2005, p. 1176.

[10] Map obtained from http://www.ne.jp/asahi/pazyfe/amistad/nanbei/ colombia/img/geografia_mapa_colombia.jpg

\section{AuthORS}

P. Teherán is with the Department of Physics, Universidad Nacional de Colombia, Carrera 30 \# 45 - 03, Bogotá, Colombia (e-mail: pdteherans@bt.unal.edu.co).

J. G. Carriazo is with the Deparment of Chemistry, Universidad Nacional de Colombia, Carrera 30 \# 45 - 03, Bogotá, Colombia (e-mail: jcarriazog@ unal.edu.co).

J. C. León is with the Department of Physics, Universidad Nacional de Colombia, Carrera 30 \# 45 - 03, Bogotá, Colombia (e-mail: jcleonl@bt.unal.edu.co).

This work was supported in part by the Universidad Nacional de Colombia, Facultad de Ciencias.

Submitted April $16^{\text {th }}, 2010$. Published as resubmitted by the authors July $13^{\text {th }}, 2010$. 